\title{
BMJ Global Health Compensating control participants when the intervention is of significant value: experience in Guatemala, India, Peru and Rwanda
}

To cite: Quinn AK, Williams K, Thompson LM, et al. Compensating control participants when the intervention is of significant value: experience in Guatemala, India, Peru and Rwanda. BMJ Global Health 2019;4:e01567. doi:10.1136/ bmjgh-2019-001567

Handling editor Seye Abimbola

- Additional material is published online only. To view please visit the journal online (http://dx.doi.org/10.1136/ bmjgh-2019-001567)

Received 18 March 2019 Revised 3 July 2019 Accepted 5 July 2019

Check for updates

(C) Author(s) (or their employer(s)) 2019. Re-use permitted under CC BY. Published by BMJ.

For numbered affiliations see end of article.

Correspondence to Dr Ashlinn K Quinn; ashlinn.quinn@nih.gov

\section{ABSTRACT}

The Household Air Pollution Intervention Network (HAPIN) trial is a randomised controlled trial in Guatemala, India, Peru and Rwanda to assess the health impact of a clean cooking intervention in households using solid biomass for cooking. The HAPIN intervention-a liquefied petroleum gas (LPG) stove and 18-month supply of LPG-has significant value in these communities, irrespective of potential health benefits. For control households, it was necessary to develop a compensation strategy that would be comparable across four settings and would address concerns about differential loss to follow-up, fairness and potential effects on household economics. Each site developed slightly different, contextually appropriate compensation packages by combining a set of uniform principles with local community input. In Guatemala, control compensation consists of coupons equivalent to the LPG stove's value that can be redeemed for the participant's choice of household items, which could include an LPG stove. In Peru, control households receive several small items during the trial, plus the intervention stove and 1 month of fuel at the trial's conclusion. Rwandan participants are given small items during the trial and a choice of a solar kit, LPG stove and four fuel refills, or cash equivalent at the end. India is the only setting in which control participants receive the intervention (LPG stove and 18 months of fuel) at the trial's end while also being compensated for their time during the trial, in accordance with local ethics committee requirements. The approaches presented here could inform compensation strategy development in future multi-country trials.

\section{INTRODUCTION}

The Household Air Pollution Intervention Network trial (HAPIN) is a multi-country randomised controlled trial (RCT) of a clean cookstove and fuel intervention for pregnant women who cook with biomass fuels, such as wood and dung. The trial seeks to evaluate the effect of switching to clean fuel cooking
Summary box

Compensation packages were developed for households randomised to the control arm of an interventional trial in Guatemala, India, Peru and Rwanda with the aim of reducing differential bias and incentivising continued engagement.

- A two-step process involving development of guiding principles followed by site-specific formative research was undertaken.

- The resultant compensation packages differed across the four sites while adhering to the overal guiding principles.

- The adaptive, context-specific approach taken here could inform control compensation in future multi-country trials.

during pregnancy and the infant's first year of life on the primary outcomes of birth weight, linear growth and severe pneumonia in the child, as well as blood pressure in older adult women who reside with the pregnant women. In total, 3200 pregnant women are being enrolled, 800 each in Guatemala, India, Peru and Rwanda. Activities are led by country-specific Intervention Research Centres (IRCs). Households randomised to the intervention arm receive a liquefied petroleum gas (LPG) stove and a continuous supply of free LPG from early pregnancy through the child's first birthday, approximately 18 months per participant. The issue of appropriate compensation for households randomised to the control arm of HAPIN was the subject of extensive discussions and data gathering during the HAPIN formative research period, reported here.

Compensation packages for participation in research vary widely, including in low-income and middle-income country settings. 
Much of the literature has concerned appropriate levels of financial compensation, reflecting the fact that cash is a typical form of compensation in the USA and Europe. ${ }^{2}$ Cash is often valued over in-kind goods because it provides maximal flexibility in how it is spent or saved. Discussions of goods-based and service-based compensation are more rare, despite the fact that these types of compensation are often provided in low-income and middle-income country settings. ${ }^{3-5}$

In randomised trials, control compensation frequently consists of deferred receipt of the intervention. HAPIN initially conceived of control compensation similarly, planning to provide control participants with a stove and 18 months of LPG at the conclusion of trial participation. In early discussions, however, this approach was deemed inadequate for HAPIN for three primary reasons.

First, HAPIN investigators worried that asking control households to wait 18 months before receiving compensation might introduce differential bias into the trial. Participation in HAPIN requires a substantial time commitment despite the fact that ethical reviews concluded that the risks of participation in HAPIN were minimal. HAPIN investigators reasoned that the free, continuous supply of cooking fuel provided to intervention households would serve as sufficient incentivisation for intervention participants to stay enrolled for the 18 months of follow-up. Control participants would not receive this ongoing benefit, and for this reason might elect not to participate in the trial (potentially leading to selection bias), or might drop out of the trial at higher rates (resulting in differential losses to follow-up between arms).

Second, it is possible that the intervention could affect health outcomes by virtue of household economics rather than via a reduction in household air pollution. Intervention households would not need to purchase or collect their own biomass fuel for the duration of the trial. Thus, the time and money previously spent on fuel could theoretically be spent in ways that could impact trial outcomes such as birth weight and child growth, for example, by diverting money that would have been spent on fuel to more nutritious food, or using time saved from collecting fuel to visit the health centre more frequently.

Lastly, HAPIN investigators were concerned about the perceptions of fairness at the community level that could emerge as a result of asking control households to participate in a trial over an 18-month period without receiving any ongoing compensation while intervention households in the same communities were receiving a valuable asset (LPG stove and free fuel) immediately. Participation in HAPIN involves visits to health clinics for ultrasound examinations and other assessments, and numerous home visits for environmental sampling, child assessments of pneumonia and anthropometry, and collection of blood spot and urine for biomarkers. The HAPIN team worried that without ongoing compensation to control households there could be resentment between households that could create social disharmony and/or make the trial unwelcome in the community.

As the team began formative research, it became clear that the original plan of deferred receipt of the intervention could create logistical, scientific and potentially ethical problems. Designing appropriate incentives for control households therefore became of paramount importance. The compensation strategy needed to achieve the same goals in four diverse settings while also being contextually appropriate and satisfying local ethics authorities.

The work described here was approved by ethics review entities at Emory University, Johns Hopkins University, Universidad del Valle de Guatemala, the Guatemalan Ministry of Health, Sri Ramachandra Institute of Higher Education and Research, the Indian Council of Medical Research, the A.B. PRISMA, the London School of Tropical Hygiene and Medicine, and the Rwandan National Ethics Committee. HAPIN is registered at clinicaltrials. gov under identifier NCT02944682.

Development of control compensation packages occurred in two phases. First, a set of multi-country principles was developed for the overall trial. Next, each IRC conducted formative research to build a package consistent with those principles and acceptable to study participants, trial investigators and ethics committees. HAPIN is currently tracking the effectiveness of these strategies at achieving the objectives mentioned earlier. This paper describes the compensation packages identified and the considerations informing their development. Outcomes will be analysed and presented after the trial concludes in 2021.

\section{GUIDING PRINCIPLES}

The principles underlying HAPIN's control compensation strategy were developed in discussions with bioethicists and ethics committees, and are shown in table 1. In short, they expressed three aims: (i) treat participants ethically, (ii) encourage controls to remain enrolled throughout the study and (iii) minimise the likelihood that the provision of LPG stoves and fuel to intervention households could create economic differences that might affect the health outcomes of the trial.

\section{SETTING-SPECIFIC COMPENSATION PLANS}

With this guidance, the IRCs designed formative research activities to further develop setting-specific compensation plans. Table 2 outlines each country's activities. Each IRC determined the contextually appropriate combination of formative research activities for their setting, according to their prior experience conducting similar activities in the area. Participants were generally drawn from pools of individuals who would be similar to HAPIN participants (eg, pregnant women or mothers with children under one from the community, their spouses and family members, and/or community members who had participated in a pilot study involving an LPG stove 
Table 1 Multi-country guidance for development of compensation strategies

$\begin{array}{ll}\text { Aims } & \text { Control households will receive compensation designed to meet } \\ & \text { three aims: (i) comply with applicable ethics requirements for } \\ & \text { treatment of controls, (ii) compensate control participants for the } \\ \text { burden associated with the study, with a view to minimising losses } & \text { to follow-up and (iii) offset the likely/potential economic advantage to } \\ \text { intervention households accorded by the provision of free stoves and } & \text { fuel }\end{array}$

Trial-wide principles

1. Control compensation should not have the potential for impacting the outcomes of interest. For example, directly providing food would not be appropriate since it could impact HAPIN outcomes such as child growth and birth weight

2. Any strategy to be incorporated into the trial cannot intentionally incentivise practices or behaviours that might put the control group at risk of adverse health outcomes. For example, provision of wood fuel would not be appropriate. On the other hand, incentives can be conditioned on continued participation in the trial

3. The strategy should be created in consideration of the potential for other adverse effects of the compensation, such as disputes about who in the household receives and can use the incentive

4. The strategies must be approved by applicable ethics committees and the HAPIN Data and Safety Monitoring Board

HAPIN, Household Air Pollution Intervention Network.

who would have familiarity with this technology and the burden of participating in a research study). The IRCs were in contact with one another throughout the design and conduct of the formative research through weekly team meetings held via teleconference. The progress and results of these activities were also discussed during an in-person meeting in September 2017.

Lastly, each HAPIN IRC used the information gathered from the formative research activities to propose compensation packages for HAPIN participants. These were subsequently presented to the HAPIN investigators, institutional ethics committees and the HAPIN Data Safety Monitoring Board for approval. In some cases, feedback from these groups was incorporated into the final packages, with major changes discussed below.

The final compensation packages for HAPIN households are described in table 3. The specifics of the compensation plans differ by IRC in terms of timing of delivery, the nature of the items provided and the total cost per household.

In Peru and Rwanda, for example, gift items will be provided to control participants at designated points throughout their participation in the trial. These items were mentioned during the formative research: sweaters and hats in the case of Peru and kitenge cloth in the case of Rwanda. At baseline, all Rwandan participants will receive a table (which serves as an LPG stove base for intervention households). At the conclusion of HAPIN participation, control households in Peru will receive an LPG stove and cooking package (stove, one cylinder of LPG and pressure cooker). Rwandan controls will be able to choose from several options at the end of the study: an LPG package, a solar kit, or a cash equivalent.

The Guatemala IRC decided on a different approach: control participants would be able to choose from a catalogue of items of varying value, with included items selected by working group members. Control households will receive a total of four coupons worth GTQ 500 (US\$67) each, which they can use to purchase items at the time of receipt or apply towards the purchase of a larger item at the study's end. The wait would increase in proportion to an item's value: higher-priced items (LPG stove, refrigerator, dining table and chairs, clothes wardrobe) would require waiting until the end of the trial. A shorter wait would be required for smaller items (eg, clothes iron, set of dishes, blender).

In India, formative research suggested that cash compensation-equivalent to the amount spent on stoves and LPG fuel for an intervention household-might be appropriate for controls. India has previously used conditional cash transfers successfully to motivate desired behaviours such as giving birth in health facilities. ${ }^{6}$ This cash-based compensation plan, however, was rejected by the Sri Ramachandra Institute of Higher Education and Research ethics board. The board stipulated that the India team must not provide monetary compensation to either study arm except to reimburse transportation costs and lost wages, and directed that at the end of the trial, the India IRC research team must provide controls with exactly the same package that intervention households receive. As this advice generally aligned with the multicountry guidance, it was decided that control households 
Table 2 Formative research activities at each Intervention Research Centre

\begin{tabular}{|c|c|c|c|}
\hline Country & Activity & Participants & Example of task \\
\hline Guatemala & Working groups & $\begin{array}{l}\text { Four working groups with } 52 \text { participants } \\
\text { total: women and their spouses and/or other } \\
\text { adult household members, all of whom } \\
\text { had participated in a pilot of the LPG stove } \\
\text { intervention }\end{array}$ & $\begin{array}{l}\text { Asked to list household items a control } \\
\text { household might like to have (within } \\
\text { constraints); top responses voted on }\end{array}$ \\
\hline \multirow[t]{2}{*}{ India } & $\begin{array}{l}\text { In-depth } \\
\text { interviews }\end{array}$ & $\begin{array}{l}20 \text { participants, with purposive mix of (1) } \\
\text { participants in an LPG pilot, (2) participants } \\
\text { considered for the pilot who did not meet } \\
\text { inclusion criteria and (3) new participants with } \\
\text { no previous study connexion }\end{array}$ & $\begin{array}{l}\text { Semi-structured interview on } \\
\text { perspectives about randomised } \\
\text { controlled trial participation, feelings } \\
\text { about selection as a control and possible } \\
\text { compensation for control participants }\end{array}$ \\
\hline & $\begin{array}{l}\text { Formal } \\
\text { discussion }\end{array}$ & Six village health nurses in study area & $\begin{array}{l}\text { Same semi-structured interview as for } \\
\text { in-depth interviews (see above) }\end{array}$ \\
\hline \multirow[t]{2}{*}{ Peru } & $\begin{array}{l}\text { In-depth } \\
\text { interviews }\end{array}$ & Seven pregnant women & $\begin{array}{l}\text { Asked about typical gifts received by } \\
\text { new mothers, typical fuel collection/ } \\
\text { purchasing practices and perceptions } \\
\text { about LPG }\end{array}$ \\
\hline & Focus group & $\begin{array}{l}\text { One discussion with seven women (either } \\
\text { pregnant or new mothers) }\end{array}$ & $\begin{array}{l}\text { Discussed common household } \\
\text { expenditures, valued items for women } \\
\text { and new mothers, and methods for } \\
\text { showing appreciation to those who } \\
\text { provide help }\end{array}$ \\
\hline \multirow[t]{2}{*}{ Rwanda } & $\begin{array}{l}\text { Survey in } \\
\text { antenatal clinics }\end{array}$ & 60 pregnant women & $\begin{array}{l}\text { Questions covered acceptability of } \\
\text { different compensation strategies, } \\
\text { including types of compensation, } \\
\text { frequency of compensation and waiting } \\
\text { periods for larger items }\end{array}$ \\
\hline & $\begin{array}{l}\text { Focus group } \\
\text { discussions }\end{array}$ & $\begin{array}{l}\text { Two discussions, each with eight former } \\
\text { participants in LPG pilot and their husbands }\end{array}$ & $\begin{array}{l}\text { Discussion of options to maintain control } \\
\text { participants' engagement and to ensure } \\
\text { participants maintain trust that the study } \\
\text { team will deliver larger items at the end of } \\
\text { the trial }\end{array}$ \\
\hline
\end{tabular}

LPG, liquefied petroleum gas.

in India would be given an LPG stove identical to the one received by intervention households, plus credit towards an equal amount of LPG. Institutional review boards and ethics boards in the other three IRCs allowed plans as proposed.

\section{LESSONS LEARNED}

Initially, HAPIN planned to compensate control participants at trial's end with a package identical to that received by intervention households: an LPG stove plus 18 months of fuel. It soon became clear that this approach presented a variety of problems, from potential to introduce differential bias into the study to concerns about the fairness of asking control households to undergo multiple study procedures over an 18-month period without ongoing compensation. After integrating input from local staff, formative research, study community members, ethics committees, and experts, the plan that emerged instead consisted of a set of compensation packages based on uniform guiding principles and adapted to the different contexts of the four IRCs. These were implemented in April 2018 as enrolment began.
As the trial progresses, HAPIN investigators are closely monitoring control compensation packages to ensure they are meeting the original goals (ie, to maximise engagement and minimise differential attrition in the control arm).

Different models for compensating research participants have been suggested in the literature. ${ }^{7-9}$ According to the free market model, participants would be paid competitive rates based on the principles of supply and demand (eg, adjusted to meet recruitment goals). Under wage-payment, payment would align with local rates for unskilled labour and would be provided based on the time participants devote to research activities. The reimbursement model suggests reimbursement of actual expenses (eg, transport and lost wages). Appreciation models suggest that research participation is less a form of labour than a type of altruistic engagement, and that compensation therefore should not be based on market rates but rather seen as an expression of gratitude for participating. These models are not mutually exclusive, and scholars have suggested that 'the best way of establishing an appropriate level of payment may be 


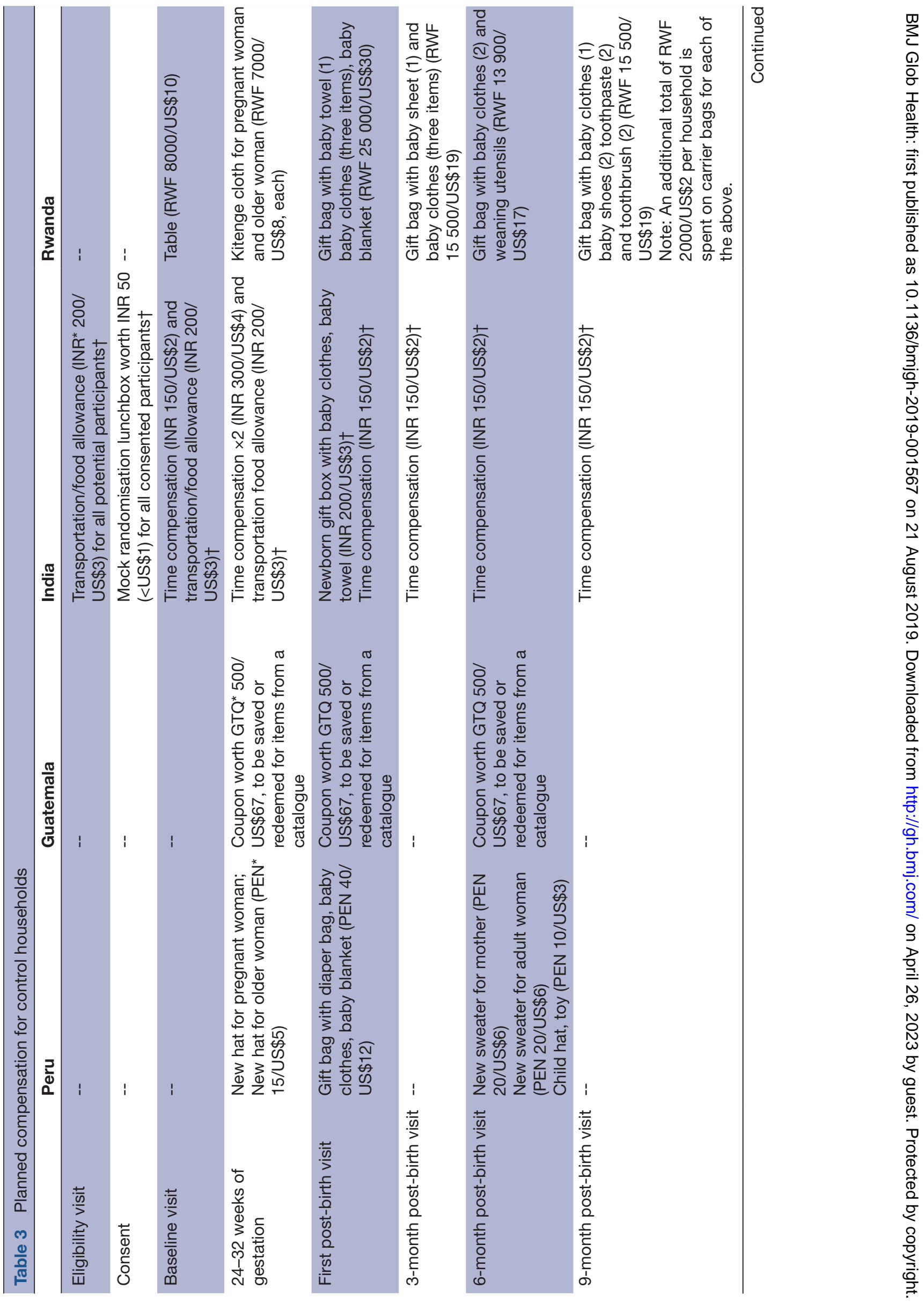




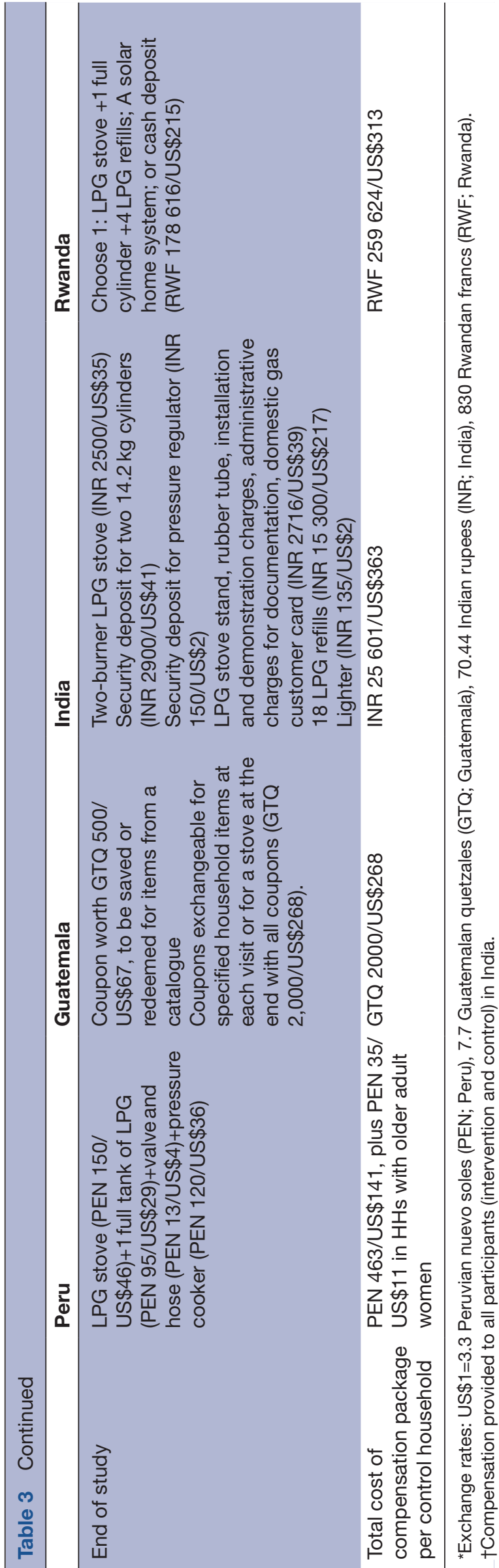

to use some combination of these different approaches, depending on the type of research being conducted'.

These models were never explicitly discussed during development of the HAPIN control compensation strategies. Examination after the fact, however, suggests that the strategies combined elements of several models. The predominant model combined 'free market' principles (because compensation levels were designed to be high enough to encourage recruitment and retention) with 'appreciation' (because in general the items providedparticularly the baby and household items-were explicitly framed as 'gifts' and thus distanced from the language of work and labour). India was the only IRC to employ the 'reimbursement' and 'wage-payment' models alongside the others, in its provision of travel and lost-wage stipends to participants.

Limited research exists on preferred compensation mechanisms in low-income and middle-income settings. Participants in a Kenya study preferred cash payments, due to their flexibility. ${ }^{5}$ However, these participants distinguished between reimbursements for direct costs (eg, transportation and lost wages) - which were highly preferred in cash-and tokens of appreciation, for which goods were preferred. An important consideration here may be that biomass-using households are on the lower end of the socioeconomic spectrum. One common argument in the literature suggests that financial remuneration is more attractive to economically disadvantaged populations and might lead to distorted perceptions of risk. ${ }^{10}$ Others, however, argue that removing cash from the menu of options for the socioeconomically disadvantaged is a form of paternalism that limits the options of research participants rather than protecting them ${ }^{8}$ and could actually disproportionately exclude poorer participants. $^{2}$

No other site besides India included cash reimbursements (for travel or wages) as compensation. Cash as a form of appreciative compensation, meanwhile, appears only in Rwanda, where a cash payment is among the options that may be chosen by control households at the conclusion of the trial. The other IRCs all decided on goods-based compensation, though some (Guatemala and Rwanda) incorporated elements of flexibility and choice into their packages.

Though not explicitly outlined in the multi-country guidance (table 1), equity between control and intervention arms came up repeatedly in community and ethics board discussions. The clearest example was in India, where an ethics board mandated that control households receive a compensation package identical to the intervention one. This makes India the only setting in which control and intervention packages are monetarily equal, each valued at US $\$ 383$ (see online Supplementary tables 1 and 3). In the other settings, the market value of the intervention package remained greater than of the control package, sometimes significantly so. In Guatemala's case, the intervention cost is US\$1414 per household versus US\$268 in compensation for each control household. 
These differences reflect the cost of achieving the aims of the intervention in each locale. Each IRC designed their intervention according to a primary objective: to provide an LPG stove, fuel and any needed additional supplies that would enable households to complete all their cooking tasks exclusively and safely with this stove and fuel. For example, in Guatemala, a griddle is needed to cook tortillas, a staple food. The Guatemalan IRC chose a three-burner stove incorporating a griddle as their intervention stove, which raised costs here. Although we believe that equity between intervention and control households in HAPIN is best calibrated to the burden on study participation rather than the financial expense of delivering the intervention, these details highlight the complexity of deciding what is 'fair' when interventions are seen as having actual market value.

In Rwanda, a key challenge uncovered during formative research was that few rural households had prior experience with LPG. Providing an LPG stove at trial's end, therefore, was not viewed as favourably in Rwanda as in India, where the nation-wide Pradhan Mantri Ujjwala Yojana campaign has increased LPG awareness and accessibility, even in rural areas. ${ }^{11}$ LPG access has also been increasing rapidly in Peru, partly due to a nation-wide government subsidy programme that provides discounted LPG to poor, rural families. ${ }^{12}$ In Rwanda, it was important to offer other compensation items valued in this community: in this case, a choice between an LPG package, a solar kit and/or a cash deposit equivalent in value to the two other options. In Guatemala, awareness of LPG was higher but formative research participants worried they would likely not be able to afford to purchase LPG regularly post-trial. The Guatemala IRC decided to allow control group participants to choose their compensation, given that an LPG stove provided at the end might have little value to households who could not afford enough fuel to use it regularly.

The third criterion for control compensation was that strategies minimise the potential economic advantage created by the LPG stoves and fuel via reductions in purchased fuel costs and in time spent cooking and collecting fuel. In the end, however, HAPIN's team concluded that the direction and strength of any potential economic effect associated with the provision of free LPG fuel to HAPIN households is not something that can be assumed a priori, but rather is a research question of its own to be investigated over the course of the trial. For example, many HAPIN participants typically collect biomass fuel themselves, drawing on abundant and accessible supplies of wood and/or animal dung. Receiving free LPG where biomass fuel is already free may confer no economic advantage that could improve health status. It is, likewise, not yet clear how much time savings will accrue from avoided fuel collection, nor how participants might spend any such extra time. As a result, plans are underway to track and evaluate the economic impact of the intervention during the HAPIN trial via dietary surveys, questionnaires and time use studies. While not available until the trial concludes, data on these outcomes will contribute to the scant extant literature on the effects of in-kind transfers on economic and health outcomes in low-income and middle-income countries (eg, Gentilini, ${ }^{13}$ Cunham $^{14}$ and McIntosh ${ }^{15}$ ).

\section{CONCLUSIONS}

This paper illustrates how formative research, guided by common principles, can be used to develop cross-cutting but locally appropriate strategies for compensating control group participants in a multi-country RCT. The diversity of compensation packages developed for HAPIN's four countries suggests that one-size-fits-all approaches may not achieve their intended goals in multicountry trials. Agreeing on general principles as central guidance, however, can usefully inform local implementation of contextually appropriate control compensation packages in low- and middle-income settings.

\section{Author affiliations}

${ }^{1}$ Fogarty International Center, National Institutes of Health, Bethesda, Maryland, USA ${ }^{2}$ Division of Pulmonary and Critical Care Medicine, Johns Hopkins University School of Medicine, Baltimore, Maryland, USA

${ }^{3}$ Nell Hodgson Woodruff School of Nursing, Emory University, Atlanta, Georgia, USA ${ }^{4}$ Department of Disease Control, Faculty of Infectious and Tropical Diseases, London School of Hygiene and Tropical Medicine, London, UK

${ }^{5}$ Centro de Estudios en Salud, Universidad del Valle de Guatemala, Guatemala City, Guatemala

${ }^{6}$ Department of Environmental Health Engineering, Sri Ramachandra Insitute of Higher Education and Research, Chennai, , India

${ }^{7}$ CRONICAS Center of Excellence in Chronic Diseases and Department of Medicine, School of Medicine, Universidad Peruana Cayetano Heredia, Lima, Peru

${ }^{8}$ Department of Environmental Health, Rollins School of Public Health, Emory University, Atlanta, Georgia, USA

${ }^{9}$ Department of International Health, Johns Hopkins Bloomberg School of Public Health, Johns Hopkins University, Baltimore, Maryland, USA

Acknowledgements We thank Dr Joseph Millum (Bioethicist, NIH) for his early guidance on the competing ethical and scientific issues in this matter. We also thank Zoë Sakas and Mayari Hengstermann for their contributions to the HAPIN formative research, the numerous research staff in each IRC and the community participants in formative research. A multidisciplinary, independent Data and Safety Monitoring Board (DSMB) appointed by the National Heart, Lung, and Blood Institute (NHLBI) monitors the quality of the data and protects the safety of patients enrolled in the HAPIN trial. DSMB members: Nalini Sathiakumar, MD, Dr PH (Chair, University of Alabama); Nancy R Cook, ScD (Harvard Medical School); Stephen Hecht, PhD (University of Minnesota); Catherine Karr, MD, PhD (University of Washington); Joseph Millum, PhD (National Institutes of Health, NIH); Paul K. Whelton, MD (Tulane University). NHLBI DSMB members: Katie H. Kavounis, MPH; Dong-Yun Kim, PhD; Lora A Reineck, MD, MS; Gail G Weinmann, MD (DSMB executive secretary). Program Coordination: Gail Rodgers, MD, Bill \& Melinda Gates Foundation; Claudia L. Thompson, PhD National Institute of Environmental Health Science (NIEHS); Mark J Parascandola, PhD, MPH, National Cancer Institute (NCl); Danuta M Krotoski, PhD Eunice Kennedy Shriver National Institute of Child Health and Human Development (NICHD); Joshua P. Rosenthal, PhD Fogarty International Center (FIC), Conception R Nierras, PhD NIH Office of Strategic Coordination Common Fund; Antonello Punturieri, MD, PhD and Barry S Schmetter, National Heart, Lung, and Blood Institute (NHLBI). The findings and conclusions in this report are those of the authors and do not necessarily represent the official position of the US National Institutes of Health or Department of Health and Human Services.

Collaborators HAPIN Investigators: Vigneswari Aravindalochanan, Kalpana Balakrishnan, Dana Boyd Barr, Vanessa Burrowes, Devan Campbell, Julia McPeek Campbell, Eduardo Canuz, Adly Castañaza, Howard Chang, William Checkley, Yunyun Chen, Marilú Chiang, Maggie L. Clark, Thomas Clasen, Rachel Craik, Mary Crocker, Victor Davila-Roman, Lisa de la Fuentes, Oscar De Léon, Anaité Diaz, Ephrem Dusabimana, Lisa Elon, Juan Gabriel Espinoza, Irma Sayury Pineda 
Fuentes, Sarada Garg, Dina Goodman, Savannah Gupton, Megan Hardison, Stella Hartinger, Steven Harvey, Phabiola Herrera, Shakir Hossen, Lindsay Jaacks, Shirin Jabbarzadeh, Michael A. Johnson, Abigail Jones, Katherine Kearns, Miles Kirby, Jacob Kremer, Margaret Laws, Jiawen Liao, Amy Lovvorn, Fiona Majorin, Eric McCollum, John McCracken, Rachel Meyers, J. Jaime Miranda, Erick Mollinedo, Lawrence Moulton, Krishnendu Mukhopadhyay, Luke Naeher, Abidan Nambajimana, Florien Ndagijimana, Azhar Nizam, Jean de Dieu Ntivuguruzwa, Aris Papageorghiou, Jennifer Peel, Ricardo Piedrahita, Ajay Pillarisetti, Naveen Puttaswamy, Elisa Puzzolo, Ashlinn Quinn, Sarah Rajkumar, Usha Ramakrishnan, David Reardon, Ghislaine Rosa, Joshua Rosenthal, P. Barry Ryan, Zoe Sakas, Sankar Sambandam, Jeremy Sarnat, Suzanne Simkovich, Sheela Sinharoy, Kirk R. Smith, Kyle Steenland, Damien Swearing, Gurusamy Thangavel, Lisa Thompson, Ashley Toenjes, Lindsay Underhill, Jean Damascene Uwizeyimana, Viviane Valdes, Amit Verma, Lance Waller, Megan Warnock, Kendra Williams, Bonnie Young

Contributors Ashlinn Quinn: drafted, edited and revised the manuscript. Contributed to development of guidance for compensation packages. Assisted with design of formative research activities and with their interpretation. Contributed to decisions about compensation as a member of the Behavioral and Economics Core (BEC) team of the trial. Kendra Williams: led research activities in Peru. Assisted with leadership of the BEC team for HAPIN within which the decisions related to the issues in the manuscript were made. Edited and revised the manuscript. Lisa M Thompson: co-led research activities in Guatemala. Contributed to decisions about compensation as a member of the BEC team. Edited and revised manuscript. Ghislaine Rosa: led research activities in Rwanda. Contributed to decisions about compensation as a member of the BEC team. Edited and revised the manuscript. Anaité Díaz-Artiga: co-led research activities in Guatemala. Contributed to decisions about compensation as a member of the BEC team. Edited and revised the manuscript. Gurusamy Thangavel: co-led research activities in India. Contributed to decisions about compensation as a member of the BEC team. Edited and revised the manuscript. Kalpana Balakrishnan: co-led research activities in India. Contributed to decisions about compensation as a member of the BEC team. Edited and revised the manuscript. J Jaime Miranda: contributed to development of guidance for compensation packages. Contributed to decisions about compensation as a member of the BEC team. Joshua P Rosenthal: contributed to development of guidance for compensation packages. Contributed to decisions about compensation as a member of the BEC team. Edited and revised the manuscript. Thomas F Clasen: drafted guidance for compensation packages. Oversaw multi-country collaboration. Edited and revised the manuscript. Steven A Harvey: contributed to development of guidance for compensation packages. Provided training on qualitative research methods to in-country teams. Led the BEC team for HAPIN within which the decisions related to the issues in the manuscript were made. Edited and revised the manuscript.

Funding The HAPIN trial is funded by the U.S. National Institutes of Health (cooperative agreement 1UM1HL134590) in collaboration with the Bill \& Melinda Gates Foundation [OPP1131279].

Competing interests №, there are no competing interests for any author.
Patient consent for publication Not required.

Provenance and peer review Not commissioned; externally peer reviewed.

Open access This is an open access article distributed in accordance with the Creative Commons Attribution 4.0 Unported (CC BY 4.0) license, which permits others to copy, redistribute, remix, transform and build upon this work for any purpose, provided the original work is properly cited, a link to the licence is given, and indication of whether changes were made. See: https://creativecommons.org/ licenses/by/4.0/.

\section{REFERENCES}

1. Molyneux S, Mulupi S, Mbaabu L, et al. Benefits and payments for research participants: experiences and views from a research centre on the Kenyan coast. BMC Med Ethics 2012;13:13.

2. Grady C. Payment of clinical research subjects. J Clin Invest 2005;115:1681-7.

3. Ndebele P, Mfutso-Bengo J, Mduluza T. Compensating clinical trial participants from limited resource settings in internationally sponsored clinical trials: a proposal. Malawi Med J 2008;20:42-5.

4. Benatar SR, Singer PA. Responsibilities in international research: a new look revisited. J Med Ethics 2010;36:194-7.

5. Njue M, Molyneux S, Kombe F, et al. Benefits in cash or in kind? a community consultation on types of benefits in health research on the Kenyan coast. PLoS One 2015;10:e0127842.

6. Lim SS, Dandona L, Hoisington JA, et al. India's Janani Suraksha Yojana, a conditional cash transfer programme to increase births in health facilities: an impact evaluation. The Lancet 2010;375:2009-23.

7. Resnik D. Bioethical issues in providing financial incentives to research participants. Medicoleg Bioeth 2015;5:35-41.

8. Permuth-Wey J, Borenstein AR. Financial remuneration for clinical and behavioral research participation: ethical and practical considerations. Ann Epidemiol 2009;19:280-5.

9. Gelinas L, Largent EA, Cohen IG, et al. A framework for ethical payment to research participants. N Engl J Med 2018;378:766-71.

10. McNeill P. Paying people to participate in research: why not? A response to Wilkinson and Moore. Bioethics 1997;11:390-6.

11. Kar A, Zerriffi H. Pradhan Mantri Ujjwala Yojana: smokeless kitchens are becoming a reality, 2018. The financial express. Available: https://www.financialexpress.com/opinion/pradhan-mantri-ujjawlayojana-smokeless-kitchens-are-becoming-a-reality/1271711/

12. Pollard SL, Williams KN, O'Brien CJ, et al. An evaluation of the Fondo de Inclusión social Energético program to promote access to liquefied petroleum gas in Peru. Energy Sustain Dev 2018;46:82-93.

13. Gentilini U. Our daily bread: what is the evidence on comparing cash versus food transfers? ContractNo.: 1420. Washington, DC: World Bank, 2014.

14. Cunha JM. Testing paternalism: cash versus In-Kind transfers. Am Econ J Appl Econ 2014;6:195-230.

15. Mclntosh C, Zeitlin A. Benchmarking a child nutrition program against cash: experimental evidence from Rwanda. Rwanda: Working paper, 2018. 